\title{
COMPOSIÇÃO DA PRODUÇÃO E QUALIDADE DA UVA EM VIDEIRA CULTIVADA SOB DUPLA PODA E REGIME MICROCLIMÁTICO ESTACIONAL CONSTRASTANTE ${ }^{1}$
}

\author{
ANTONIO ODAIR SANTOS ${ }^{2}$, JOSÉ LUIZ HERNANDES ${ }^{3}$ \\ MÁRIO JOSÉ PEDRO JUNIOR ${ }^{4}$, SÔNIA ELISABETE PEREIRA ${ }^{5}$
}

RESUMO- Em São Paulo, destaca-se a viticultura como atividade familiar de caráter artesanal. Nas bacias de maior concentração atual da vitivinicultura, ocorre um período chuvoso que se estende de novembro a fevereiro, que alcança grande parte das variedades da região em fase de crescimento e maturação da baga, o que afeta negativamente a qualidade da uva e do vinho artesanal, na maioria das safras. Por outro lado, nas mesmas regiões, ocorre um período mais favorável, que é o outono/inverno com potencial de soma térmica adequado ao crescimento da videira e com incidência de um longo período de baixa pluviometria, entre os meses de abril e outubro. Um experimento foi conduzido em Jundiaí (SP), região de média altitude (700 $\mathrm{m}$ ), com variedades de uvas híbridas e fina, no qual, objetivou-se estudar os impactos ecofisiológicos do cultivo da videira conduzida sob dupla poda, forçando-se a condução das plantas por quatro estações de cultivo sequenciais de verão e inverno; analisaram-se aspectos da ecofiosologia da cultura e a composição quali-quantitativa do rendimento. Os resultados mostram que a estação de outono-inverno apresenta condições mais favoráveis à maturação fenólica das bagas, com chuvas mais bem distribuídas e desconcentradas no período do estabelecimento do fruto à colheita. A uva colhida na estação de outono-inverno apresentou maiores índices de pigmentação fenólica em relação à estação de cultivo tradicional, sendo que o controle do nível de reservas da planta revelou influência da dupla poda sequencial sobre esta variável, o que inspira práticas de manejo específicas para este tipo de exploração da videira.

Termos para indexação: Viticultura, vinho, poda.

\section{YIELD AND QUALITY COMPOSITION OF GRAPEVINES UNDER DOUBLE PRUNING AND CONTRASTING SEAZONAL MICROCLIMATE}

\begin{abstract}
In the State of São Paulo (Brazil) stands out the viticulture as an artisanal agricultural small business. In the regions of greatest clustering of vintners there is a well know rainy time frame that coincides with the period of grape growing and maturation. This contributes to drawbacks in the grape and wine quality in most of the harvestings. Nevertheless, in the same region, the time frame of autumn-winter has more favorable conditions, in this aspect, presenting a proper heat summation for grape growing and a more pronounced rainless time from April to October. An experiment was carried out in the location of Jundiai (SP) in the mid-highlands and hybrids and Vitis vinifera varieties were tested. The aim of the study was analyze the ecophysiological implication of cultivating the grapevines under double pruning through four sequential growing seasons; grape composition and yield were verified alongside with berry wet chemistry in order to check out the must quality in the contrasting time frames, winter and summer harvest. Results showed more favorable conditions for berry phenolic maturation in the autumn-winter due to a better distribution of rain as the berry set and maturation were located in the rainless period. Phenolic pigmentation was higher for the grape harvest in the winter and the plant control of assimilates revealed the double pruning as influential on it. These suggest specific management practices for this kind of grapevine cultivation.
\end{abstract}

Index terms: Viticulture, wine, pruning.

\footnotetext{
'(Trabalho 026-11). Recebido em: 04-01-2011. Aceito para publicação em: 18-07-2011.

${ }^{2}$ Eng. Agr. Dr. PqC, Centro de Engenharia, IAC, Jundiaí, SP, Rod. Dom Gabriel Paulino Bueno Couto, Km 65. Caixa Postal 26, CEP 13212-240, Jundiaí, SP, Brasil. E-mail: odairsan@iac.sp.gov.br - Pesquisador CNPq

${ }^{3}$ Biólogo MS., PqC Centro de Fruticultura, IAC, Jundiaí, SP, Brasil, e-mail: jlhernandes@iac.sp.gov.br

${ }^{4}$ Eng. Agr. Dr., Centro de Ecofisiologia e Biofísica, IAC, Campinas, SP, Brasil, e-mail: mpedro@iac.sp.gov.br Pesquisador CNPq

${ }^{5}$ Bióloga, MS., Centro de Engenharia, IAC, Jundaí, SP, Brasil, e-mail: spereira@iac.sp.gov.br
} 


\section{INTRODUÇÃO}

A qualidade do vinho e do suco de uva depende das condições ambientais existentes para a maturação da baga (acúmulo de açúcar e acidez da maturação fenólica) (MANDELLI, 2003). A maturação da uva é influenciada pela temperatura média do ar, sendo melhor o desempenho dentro de uma faixa ótima de ocorrência, fora da qual o processo de maturação pode ganhar ou perder intensidade. De igual importância são os níveis de incidência da radiação solar, a dinâmica da água no sistema soloplanta-atmosfera, dentre outras variáveis.

A videira possui mecanismos fisiológicos de autorregulação, direcionando suas reservas para vigor (crescimento vegetativo) ou frutificação (crescimento reprodutivo), de acordo com suas próprias necessidades (POMMER et al. ,2003). Geralmente em vitivinicultura, objetiva-se adotar estratégias de fisiologia de manejo, para direcionar os recursos da planta para a qualidade da produção, tal como acúmulo de precursores de fenóis, o que permitirá maior complexidade de sabor e aroma e maior expressão varietal (WAMPLE; SMTHYMAN, 2000). Tipicamente, um vinho superior requer bagas de uva que tenham uma razão casca/suco alta, pois a maior parte dos fenóis extraíveis está na casca. A razão citada depende de se ter cachos com bagas de menor tamanho. Almejam-se uvas provenientes de vinhedos com baixa produtividade, ou com um ajuste da carga que represente o equilíbrio entre a massa de cachos e a massa vegetativa,visando à maior concentração de sabor e aroma na baga (GUROVICH: PAEZ, 2004).

Para a obtenção de uvas com índices de maturação adequados, a videira vinífera necessita de inverno frio, primavera com temperaturas amenas e verão quente e seco, para expressar o seu maior potencial em sabor e aroma. Além disso, uma razoável diferença entre temperatura diurna e noturna auxilia na síntese de polifenóis (RIBÉREAU-GAYON, 1954; JACKSON ; LOMBARD, 1993; DELOIRE et al.; 2002). Mais especificamente, as condições microclimáticas reinantes durante o desenvolvimento e maturação da bagasão fundamentais para o desenvolvimento de precursores de aroma e sabor, que determinarão o grau de complexidade e perfil sensorial do vinho (JACKSON; LOMBARDI, 1993). Nesta fase, ácidos orgânicos, terpenos, monoterpenos, polifenóis-flavonoides e não flavonoides, dentre outras substâncias, estarão sob biossíntese, e as condições de "terroir" determinarão a qualidade da uva branca e tinta, e seu potencial para vinificação (GRAHAM, 1992).

A disponibilidade hídrica tem grande impacto sobre a qualidade da produção da videira; particularmente a dinâmica da água no solo, incidente na fase do estabelecimento do fruto até a colheita, tem forte influência sobre a pigmentação fenólica, o que por si influencia a complexidade do vinho e do suco produzidos (DELOIRE et al., 2005; DELOIRE et al., 2002; SANTOS; KAYE 2009). Alguns autores têm citado resultados favoráveis á qualidade da uva, quando um déficit hídrico controlado e de baixa magnitude é aplicado da fase do crescimento do fruto até a colheita (OJEDA et al., 2004). Em suma, as condições edafo-climáticas de crescimento e desenvolvimento vegetativo e reprodutivo da videira condicionam as condições da maturação da uva na colheita e, portanto, a complexidade em sabor e aroma do vinho e suco produzidos.

No Estado de São Paulo, nas regiões da "média altitude" (ao redor de $700 \mathrm{~m}$ ), existem condições microclimáticas e da dinâmica da água no solo, que são contrastantes, se considerarmos as duas estações existentes para cultivo, ou seja, a estação tradicional de primavera-verão e, alternativamente, a de outono-inverno. Dentre os fatores mais importantes, está a disponibilidade hídrica, que se dá de modo diferente em relação ao desenvolvimento do ciclo da videira, nas duas estações. Uma distribuição de chuva diferenciada condiciona um padrão de concentração que caracteriza claramente uma estação com a chuva mais concentrada na colheita e a outra com esta concentração localizada mais na fase de crescimento dos ramos, de acordo com a Normal climática da região (PEDRO-JR et al., 2004). Nenhum estudo detalhou ainda, claramente, os impactos deste perfil microclimático sobre a qualidade da uva na região, quando se conduz a videira em dupla poda. Portanto, este trabalho objetivou avaliar comparativamente a produtividade, a composição do rendimento e aspectos da qualidade da produção da videira conduzida na primavera/verão com aquela cultivada no outono/ inverno, em ciclo sequencial, sob dupla poda.

\section{MATERIAL E MÉTODOS}

O experimento foi conduzido de 2008 a 2010 , em vinhedos das cultivares Isabel, IAC-138-22Máximo e Rubi-Cabernet, enxertados sobre quatro porta-enxertos, sendo: IAC-766 Campinas, Ripária do Traviú, IAC-572 Jales e SO4. O delineamento experimental utilizado foi o de blocos casualizados, com quatro repetições. Cada parcela experimental contou com seis plantas, sendo o espaçamento adotado de $2 \mathrm{~m}$ x $1 \mathrm{~m}$, e o sistema de condução em cordão bilateral com sistema de sustentação em espaldeira alta, com fiação dupla para condução independente 
de amarração (alceamento). As videiras foram estabelecidas no ano de 2005.

Os vinhedos foram submetidos à dupla poda sequencial. A poda de produção de inverno foi realizada nos meses de janeiro/fevereiro de 2008/2009, e a poda de produção de verão foi feita nos meses de julho/agosto de 2009/2010. Podas curtas foram realizadas, deixando-se 2 a 3 gemas por esporão no inverno e varas de 5 a 6 gemas no verão; utilizou-se Dormex ${ }^{\circledR}(4 \%)$ para a indução da quebra de dormência. Para todas as safras, a totalidade do experimento foi podado num mesmo dia, mas a colheita de cada uma das variedades foi efetuada obedecendo-se ao ciclo vegetativo de cada uma delas. Durante o período vegetativo, foram feitas as desbrotas, eliminando-se os brotos laterais e o broto apical dos ramos. Os tratos culturais foram feitos como recomendado para a região, e os tratamentos fitossanitários para controle de doenças fúngicas foram realizados com a aplicação semanal de fungicidas cúpricos e mancozeb.

Foram avaliados dados do microclima, aspectos fenológicos, composição do rendimento e parâmetros descritores da qualidade da uva à vinificação; para a qualidade da baga, foi utilizada a colorimetria nas duas primeiras estações de crescimento; para as últimas safras, a colorimetria foi complementada pela análise da pigmentação fenólica (antocianina, totais fenólicos, taninos).

Para a determinação dos índices colorimétricos, indicativos da qualidade da uva, foi feita a fermentação de $5 \mathrm{~kg}$ de uva amostrada nos tratamentos. Procedeu-se à vinificação até a fase da descuba, quando se submeteram as amostras a espectrofotômetro, para leituras nos comprimentos de ondas de $420 \mathrm{~nm}$ e $520 \mathrm{~nm}$ (ILAND et al., 2004).

O teor de sólidos solúveis presentes nas amostras foi determinado por refratômetro manual, com escala de 0 a $32^{\circ}$ Brix, a partir de amostras compostas nos tratamentos.

Para determinação de níveis de Antocianinas e totais fenólicos, foram colhidas amostras compostas de 50 bagas de uva, em cada tratamento. As bagas foram homogeneizadas com mixer, e sobre o macerado resultante foi feita extração com etanol hidratado, sob agitação; posteriormente, adicionou-se HCL 1M às amostras e fez-se a leitura em espectrofotômetro, seguindo-se procedimento descrito por Iland et al. (2004); as determinações de taninos totais foram feitas utilizando-se da mesma amostragem anterior, e sobre o macerado homogeneizado procedeu-se á precipitação dos taninos através de metil-celulose, com posterior leitura em espectrofotômetro, seguindo-se metodologia descrita por Sarneckis et al.(2006).

Ao lado da área experimental, foi instalada uma estação meteorológica automática, e foram coletados dados sobre radiação solar, temperatura média do ar, precipitação pluviométrica e velocidade média do vento. Os dados foram armazenados com intervalo de 30 minutos, ao longo das safras.

Os valores médios obtidos das variáveis fenológicas e fitotécnicas foram submetidos à análise de variância e comparação de médias, pelo teste de Tukey, a 5\% de probabilidade.

\section{RESULTADOS E DISCUSSÃO}

\section{Análise microclimática no período e local do experimento}

A faixa de tempo, onde se concentrou o experimento, caracterizou-se por duas estações de produção de verão e duas de inverno. As Figuras de 1 a 4mostram o perfil microclimático do local e época experimental, onde se incluem os extratos do balanço hídrico (THORNWAITHE ; MATTER, 1955) operacionalizado segundo Rolim et al. (1998), com a evapotranspiração modelada de acordo com Santos et al. (2000).

\section{$1^{a}$ estação de produção (cultivo de verão)}

Para a primeira estação de produção, que se iniciou em julho de 2008, a temperatura média incidente nos tratamentos oscilou ao redor de $20^{\circ} \mathrm{C}$ ao longo da estação (Figura 1). A evapotranspiração da cultura elevou-se lentamente até a colheita, mostrando picos ao redor de $4 \mathrm{~mm}$ diários e estacionando na colheita em valores entre 3 e $4 \mathrm{~mm}$ diários, ou seja, 3-4 litros de água $/ \mathrm{m}^{2}$ transferidos para a atmosfera. Pode-se considerar esse fenômeno um caso de média demanda atmosférica. Esse fato mostra que a videira cultivada na média altitude paulista cursa o ciclo completo sem a incidência de grande déficit de pressão de vapor, fato que se observou nos dois verões enquadrados no experimento com as três variedades descritas. Por essa razão, os valores de potencial da água na folha, que em outras regiões mais áridas são considerados críticos para a região em questão, os mesmos valores não são indicadores de estresse severo para o caso da estação de produção do verão.

Pela Figura 1, nota-se que houve uma queda no índice ETc/ETp ao redor da floração das variedades testadas, pelo abaixamento do armazenamento da água no solo (ARM), o que é normal para a estação de produção em tela. No entanto, o extrato do balanço hídrico (Figura 1) evidencia que a queda no ARM causou um déficit hídrico de pouca expressão. Por outro lado, nota-se que ocorre incidência de excedente hídrico ainda antes do "veraison" para todas as variedades. 
As condições dadas permitem concluir que o dossel da videira, na primeira estação de produção, esteve submetido a um verão típico de acordo com a normal climática para a região; ou seja, início do ciclo com os menores índices de chuva e ocorrência de chuvas mais intensas no período do estabelecimento do fruto até a colheita.

\section{$2^{a}$ estação de produção (cultivo de inverno)}

A segunda estação de produção, de inverno, caracterizou-se por temperatura média oscilando ao redor de 20 graus no início da estação de produção, mas com leve declínio após o "veraison". Observase para esta estação uma incidência extrema de temperatura, que oscilou abaixo da temperatura-base $\left(10^{\circ} \mathrm{C}\right)$, porém com uma única ocorrência (Figura 2).

A evapotranspiração da cultura (ETc) declina lentamente da poda até a colheita, evidenciando a passagem de uma condição de média demanda atmosférica para um estado de média-baixa demanda na fase da colheita. Ocorre queda nos índices ETc/ ETp ao redor da floração, seguindo até próximo ao "veraison", pelo abaixamento do armazenamento da água no solo. Com o abaixamento do ARM, um déficit hídrico é observado, pois nesta época a ETc é mais alta (Figura 2). Assim, condições de demanda atmosféricas locais da época evidenciaram a ocorrência de um déficit hídrico de fraco a moderado, captado na "câmara de Shollander" em valores mínimos de -1,3 MPa. Nota-se que um excedente hídrico está presente somente próximo a colheita, mostrando que as chuvas se desconcentraram e foram mais bem distribuídas, na comparação com a safra de verão anterior. Numa comparação mais estendida com a estação anterior, nota-se que, nesta estação de inverno (Tabela 1;Figura 2), choveu menos, e a ETc foi menor, assim como foi menor a soma térmica e os dias com ocorrência de chuva acima de $5 \mathrm{~mm}$. Devido à época de poda adotada, nesta estação o déficit hídrico ocorreu antes da floração/"veraison", quando o ideal seria a concentração do mesmo entre a floração e a colheita.

Pelos dados da Figura 2, conclui-se que esta estação de produção hibernal foi atípica, de acordo com a Normal climática para a região (PEDRO-JR et al., 2004), ou seja, a variação do armazenamento da água no solo inverteu-se, sendo menor já no início da estação, quando de acordo com a Normal climática, o decréscimo nos valores do ARM tem lugar após a fase de maior crescimento vegetativo.

\section{$3^{a}$ estação de produção (cultivo de verão)}

Para a terceira safra, de verão, nota-se pela Figura 3 que a temperatura média oscilou ao redor de 20 graus ao longo da estação, com leve elevação após o "veraison". A evapotranspiração da cultura (Etc) eleva-se lentamente da poda até a colheita. Os dados mostram que, durante a poda, as condições atmosféricas são de média-baixa demanda evaporativa, atingindo na colheita condições de média demanda. Ocorre uma queda nos índices Etc/ETp ao redor da floração, seguindo até próximo ao "veraison", o que foi causado pelo abaixamento do armazenamento da água no solo. Contudo, mesmo com este abaixamento da água no solo, o déficit hídrico observado é de pouca expressão. As condições de demanda evaporativa atmosférica, da época e local, resultaram em uma condição de ausência de déficit hídrico significativo, o que foi sensoriado no dossel da vegetação, onde se obtiveram leituras mínimas no potencial da água na folha,de apenas -1,0 MPa; observa-se um excedente hídrico que é concentrado do "veraison" à colheita, mostrando que as chuvas se concentraram nesta fase, caracterizando-se por distribuição desfavorável, típica para a região.

Esta estação de produção foi a estação com a maior incidência de precipitação pluviométrica (Tabela 5), sendo também a que teve maior número de dias com chuva acima de $5 \mathrm{~mm}$ (Tabela 1). No entanto, a soma térmica observada foi semelhante àquela observada para a estação de verão anterior. A estação, no entanto, transcorreu de acordo com a Normal climática para a região, sendo uma estação típica, muito embora muito chuvosa e com a chuva altamente concentrada em uma fase de crescimento da videira.

\section{$4^{a}$ estação de produção (cultivo de inverno)}

Para a quarta estação de produção analisada, a temperatura média na fase da poda iniciou uma marcha de oscilação ao redor de $20{ }^{\circ} \mathrm{C}$ que se estende ao longo da estação, com um leve declino após o "verasion" (Figura 4). Nenhuma incidência extrema nesta variável foi observada, não tendo a temperatura média oscilado abaixo da temperatura base $\left(10^{\circ} \mathrm{C}\right)$. A marcha das temperaturas mínimas (Figura 5), de modo geral, teve um comportamento semelhante nas duas estações de crescimento de inverno analisadas, porém o padrão de oscilação das temperaturas mínimas foi diferente. Nesta última estação, as oscilações na temperatura tiveram patamares superiores, porém algumas massas polares permaneceram por mais tempo sobre a região, ocasionando uma exposição maior a baixas temperaturas.

A evapotranspiração da cultura apresenta um 
padrão de declínio da poda até a colheita, de modo semelhante à estação de produção de inverno anterior. Observa-se um decréscimo no armazenamento da água no solo ainda na fase de desenvolvimento e crescimento dos ramos. Este fato, em combinação com as condições de demanda evaporativa atmosféricas reinantes, no local e época, levaram à captação, no dossel da cultura, de valores mínimos de potencial da água na folha em -1,3 MPa (Tabela 1). Um excedente hídrico mínimo é observado próximo da colheita (Figura 7), mostrando que as chuvas se desconcentraram e foram mais bem distribuídas do que as estações anteriores de verão. O número de dias com chuva acima de $5 \mathrm{~mm}$ é o menor observado entre as estações. No entanto, as somas térmicas foram as menores observadas, mostrando que estações com estas características não são adequadas para instalação de variedades de ciclo longo e mais exigentes em soma térmica. Numa análise geral, a estação transcorreu dentro dos padrões de tipicidade da normal climática, com a evolução temporal dos valores de armazenamento da água no solo numa marcha invertida em relação à estação de verão.

A análise da Figura 5 evidencia que amplitudes térmicas ao redor de $20{ }^{\circ} \mathrm{C}$ são observadas nas safras de inverno, enquanto para as safras de verão estes valores oscilam abaixo de $15{ }^{\circ} \mathrm{C}$; portanto, a amplitude térmica tende a ser maior durante as safras de inverno, fato que tem implicância para a biossíntese de polifenóis, que são favorecidos nestas condições. Doravante, estas condições, somadas à melhor distribuição de chuvas incidentes na SI (Tabela 1), evidenciam fatores de forte influência sobre a qualidade da uva. De fato, Jackson e Lombardi (1993) e Jackson (1994), dentre outros, mostram que as rotas metabólicas, para o acúmulo da pigmentação fenólica (antocianina, polifenóis totais, taninos), são fortemente influenciadas pela dinâmica da água no solo e pela amplitude térmica. Doravante, Francis et al. (1999) comprovaram cientificamente a ligação entre pigmentação fenólica e complexidade do vinho em sabor e aroma.

Outros autores relataram amplitudes térmicas ao redor de $20{ }^{\circ} \mathrm{C}$, em cultivo de inverno, para a videira, na mesma topossequência da bacia do Rio Jundiaí. De fato, Amorim et al. (2005) mostraram, para média e alta altitude mineira, condições semelhantes àquelas encontradas neste trabalho. Os autores mostraram maior rendimento em pigmentação fenólica no cultivo de inverno, quando se testaram variedades de Vitis vinifera.

Nas Tabelas 2 e 3, nota-se uma tendência na diminuição no peso de cachos e no peso de baga da SV para SI, para a maioria das combinações copa/ porta-enxerto estudadas. $\mathrm{O}$ ambiente de crescimento e desenvolvimento da baga deu-se num ambiente de melhor distribuição hídrica, que foi o cultivo de inverno, onde o desenvolvimento inicial da baga ocorre em situação de condições hídricas mais favoráveis, principalmente quanto à localização no tempo, da época em que é mais importante a divisão celular, fator que influencia no tamanho e peso final da baga (JACKSON, 1994). Ressalte-se que a diminuição de peso discutida foi observada, mesmo tendo-se produzido a SI com base em gemas mais distantes da base do ramo primário (poda em vara), na comparação com a SV, onde se utilizou a poda curta. Vários autores relataram peso de cacho e fertilidade de gemas crescentes da base à porção mediana do ramo maduro (DRY, 2000; LEÃO ; SILVA, 2003).

$\mathrm{Na}$ análise individual, por porta-enxertos testados ao longo do estudo, observa-se que se destaca em produtividade final a combinação entre Isabel e o porta-enxerto Traviú. Para IAC-Máximo,o melhor desempenho foi para a combinação com IAC-766 e Traviú (Tabela 5). Na média obtida em todas as combinações com os porta-enxertos, ao longo das safras, nota-se que a variedade Isabel não se diferenciou em produtividade, enquanto para IAC Máximo ocorre maior contraste entre as produtividades alcançadas na segunda e terceira estações de crescimento.

Numa análise geral, o peso de cachos e a produção por planta tendem a cair do verão para o inverno, em todas as sequências verão/inverno, considerando-se individualmente cada porta-enxerto. Essa oscilação entre inverno e verão também é evidente no peso médio alcançado nos ramos.

Para Rubi-Cabernet,ocorre menor flutuação na produtividade na sequência de safras. Este fato evidencia o "status" de uma variedade de V.vinifera, muito mais estável na comparação com variedades americanas ou híbridas, mesmo sob regime de poda contínua. Doravante, evidencia-se o potencial de resistência à incidência de variáveis extremas, como modificação do regime de poda e variações microclimáticas, para variedades de ciclo mais longo, que tendem a ser mais estáveis, como demonstrou a variedade Rubi Cabernet. Para uma variedade $V$. vinifera, as mudanças fenológicas são mais lentas, assim como a maturação da baga. O melhor resultado para produtividade, no caso de Rubi Cabernet, foi quando associada ao porta-enxerto 766 (Tabela 5).

Ressalte-se que, na análise temporal, entre safras, o significado estatístico de uma análise deve ser pesado concomitantemente ao fato de que os tratamentos não estão sujeitos às mesmas condições experimentais, quanto à dinâmica da água e incidência microclimática, principalmente. Por este fato, 
na análise de resultados em viticultura e enologia, é muito importante amostrar a campo os tratamentos e verificar na análise química a evolução da qualidade, como fator de comprovação de resultados. No entanto, em termos de componentes do rendimento, está evidenciado neste trabalho que há uma queda nos índices de produção da safra de verão para a de inverno, principalmente para as variedades Isabel e IAC Máximo.

A combinação das variedades Isabel, Máximo e Rubi-Cabernet com IAC-766 e Traviú resultou nas relações copa/porta-enxerto que mais desenvolveram massa vegetativa ao longo das safras (Tabela 6).

Numa análise da dinâmica da acumulação de reservas na videira, considerando-se todas as combinações testadas, nas diversas estações de produção, nota-se, pelo peso médio de ramos, que houve uma flutuação nesta variável (Tabela 6; Figura 5). Ocorre uma grande oscilação com pico de máxima na terceira safra, com destaque para Isabel. Este fato tem origem no verão chuvoso da terceira safra, que foi a safra com maior disponibilidade hídrica dentre todas as analisadas. A flutuação discutida, no entanto, diminui para caso de IAC Máximo e Rubi Cabernet. É importante destacar que, mesmo com o grande contraste entre a disponibilidade hídrica desta estação mais chuvosa ( $3^{\mathrm{a}}$ estação) com o inverno seguinte ( $4^{\mathrm{a}}$ estação), tipicamente mais seco, a variedade Isabel não acumulou maiores valores em antocianina, do cultivo de verão para o de inverno (Tabela 9), fato que demonstra a grande dificuldade desta variedade em atingir índices mais altos de cor, mesmo sob condições mais favoráveis, na comparação com as outras variedades híbridas. Esta dificuldade parece estar relacionada mais à característica intrínseca da cultivar que à diferença de ciclo, uma vez que a diferença de dias da poda à colheita entre Isabel e Máximo, que variou entre 3 e 11 dias nas diferentes safras, parece não ser suficiente para interferir climaticamente nesta variável

Por outro lado, para Rubi Cabernet, observase que, quando combinada com IAC 766 e Traviú, resultou em maior massa de ramos. No entanto, para a produtividade, destaca-se a combinação com Traviú como a de pior desempenho, mostrando que uma mesma combinação entre copa e porta-enxerto pode ter vocação diferente quanto à produção de massa vegetativa e produtividade.

Para fertilidade de gemas, a comparação entre safras fica dificultada por ter sido adotado alturas de podas diferentes, para SI e SV, resultando em posições de gemas remanescentes diferentes. Por outro lado, dentro da mesma safra, e, tomando-se as variedades isoladamente, nota-se que a combinação das mesmas com o porta-enxerto IAC 766 resultou em valores mais elevados em fertilidade de gemas, na maioria dos casos (Tabela 7).

Notadamente para a variedade Isabel, o maior acúmulo de reservas, medido pela massa de ramos acumulada na estação mais chuvosa, não foi necessariamente um indício de maior acúmulo de sólidos solúveis (Tabela 8), o que resultou, porém, em maior fertilidade de gemas para aquela safra, na comparação com as outras variedades. Portanto, os dados sugerem que a variedade Isabel, em espaçamentos maiores, tem grandes chances de incrementar a produção por área, com base na formação de uma planta maior, com arquitetura do dossel que privilegie maior índice de área foliar e maior massa de ramos; por outro lado, não há uma tendência mostrando que isto levará a um acúmulo maior de sólidos solúveis $\left({ }^{\circ}\right.$ Brix $)$, mesmo sob clima mais favorável, como a estação de outono/inverno. Este fato tem particular importância para a eventualidade da condução desta variedade sob poda e colheita mecanizada, já que maiores espaçamentos são mais favoráveis à padronização desta prática.

As variedades Isabel e IAC Máximo apresentaram ciclo mais curto na safra de inverno, sendo um comportamento inverso ao da variedade $V$. vinifera em teste, ou seja, Rubi Cabernet (Tabela 7). As variedades híbridas ou americanas de ciclo curto podem ter um comportamento aleatório quanto à duração do ciclo, quando cultivadas extemporaneamente. Sendo já de ciclo curto, são menos afetadas pelas condições microclimáticas, ficando menos expostas a riscos de incidência de extremos.

A variedade Rubi Cabernet encurtou o tempo para a atingir a floração e a fase do "veraison", do cultivo de verão para o de inverno; no entanto, no cômputo geral sempre apresentou ciclo mais longo no inverno.

Quanto à duração do ciclo, não foi feito um cômputo separado por porta-enxerto, devido ao agrupamento que foi feito para a colheita final pelos índices médios de maturação. No entanto, para as fases intermediárias, observa-se que não houve tendência destacada de nenhum porta-enxerto em retardar ou acelerar as fases fenológicas da floração e "verasion".

Na Tabela 8, verificam-se os índices colorimétricos, que são um indicativo da concentração de pigmentação fenólica. Quanto mais intenso (maior valor), maior também é o teor da pigmentação, já que a constituição do índice está baseada no pico de absorção para a faixa do vermelho. É notório, a partir de vários resultados de pesquisa, que a disponibilidade hídrica afeta diretamente a constituição 
fenólica da uva (FLEET, 1994). Santose Kaye (2009) mostraram que, para Syrah, um estresse de fraco a moderado, do estabelecimento do fruto à floração, foi uma forçante positiva para maior pigmentação fenólica, melhorando a qualidade da baga. Deloire et al. (2002) e Ojeda et al. (2004), trabalhando com estresse hídrico controlado, aplicado a videiras $V$. viniferas, demonstraram a resposta diferencial positiva da videira a um estresse hídrico crescente, de fraco a moderado, quando aplicado do estabelecimento do fruto à maturação fenólica.

Na Tabela 8, os índices indicam que a intensidade de cor aumenta do verão para o inverno, o que resulta do impacto da distribuição da água no solo, nas duas épocas de cultivo, ou seja, no cultivo de inverno, obteve-se o melhor rendimento em qualidade. Este fato é evidente em todas as quatro safras analisadas.

A tonalidade de cor, sendo uma relação entre o pico de absorção do vermelho (A520) com o pico de absorção para o marrom (A420), dá uma indicação sobre a tendência do tom. Na primeira e segunda podas, é evidente que a tendência é mais para o tom avermelhado, no cultivo de inverno, para Isabel e IAC Máximo, em todos os porta-enxertos. Esta tendência também se confirma na terceira e quarta podas.

Para as duas últimas estações de crescimento, houve a inclusão de medições diretas da pigmentação fenólica, separando-se antocianina, polifenóis totais e taninos. Nas duas últimas safras, nota-se que, para a variedade Isabel, no cultivo de inverno, houve uma tendência oscilante em função dos portaenxertos utilizados, ora diminuindo, ora aumentando os níveis de antocianina (Tabela 8). Para polifenóis totais, no entanto, houve aumento geral do cultivo de verão para o de inverno, independentemente do porta-enxerto utilizado. Além disso, para 'Isabel, os valores em taninos são sempre muitos baixos, tanto no inverno como no verão. Numa análise geral, esta variedade apresentou a mais baixa pigmentação, fato já notório pela sua baixa capacidade de sintetizar, principalmente antocianina, não por acaso uma variedade que não atinge facilmente níveis altos de pigmentação corante. Por outro lado, nota-se que a variedade IAC Máximo tem a maior capacidade de síntese de antocianina, na comparação com as outras, e esta síntese é maior no inverno.

Para as variedades Isabel e IAC Máximo, a síntese de polifenóis totais e taninos também segue a mesma tendência, ocorrendo o maior acúmulo na safra de inverno. A variedade Rubi Cabernet, muito embora tenha acumulado mais polifenóis totais no inverno, quando se observam os taninos, separadamente, vê-se que a mesma teve acúmulo menor no inverno. Este fato demonstra a baixa adaptabilidade desta variedade no espaçamento de condução em estudo e/ou combinação copa/porta-enxerto utilizado, sendo que a mesma, apesar de um rendimento em IAF e acúmulo de reservas satisfatório, não atingiu nível de vinificação em nenhuma das safras analisadas, tanto pelos teores de polifenóis e de açúcar, como pelos teores alcançados em acidez total e $\mathrm{pH}$. A variedade não alcançou o rendimento em qualidade comparáveis àqueles alcançados pela variedade Syrah, cultivada no outono/inverno, o que foi demonstrado em estudo similar para a mesma região climática. Neste caso, a mesma logrou alcançar pigmentação fenólica e teor de sólidos solúveis em muito comparáveis às melhores regiões produtoras na altitude Catarinense (SANTOS et al., 2011; prelo).

Quanto ao acúmulo de sólidos solúveis, representado pelo índice refratométrico ( $\left.{ }^{\circ} \mathrm{Brix}\right)$, nota-se que as variedades analisadas atingiram valores pouco superiores a 15 , sendo mais elevado para as safras de inverno. Para a safra de verão (2009), sendo este a época de cultivo mais chuvosa, a ocorrência do pico de elevação na massa de reservas das vinhas, medido no peso médio de ramos, não foi um fator de elevação do nível de sólidos solúveis. A variedade IAC Máximo não mudou substancialmente os níveis de açúcar produzidos, quando o pico de reservas acumulado nos ramos teve sua maior ascensão na safra de verão/2009. Isso mostra que o acúmulo de açúcar nesta variedade não depende exclusivamente da elevação do IAF, no espaçamento tradicional de cultivo.

A variedade Rubi Cabernet, sendo uma variedade mais eficiente em acumular açúcar, teve um desempenho abaixo dos níveis descritos para a mesma em climas semelhantes ao do experimento. Notadamente neste experimento, trabalhou-se com um vinhedo abaixo de sete anos, ainda em fase de estabilização, mas pelos dados da Figura 6 e Tabela 6 pode-se inferir que, em espaçamentos mais amplos, $o$ rendimento em qualidade da produção desta variedade poderia ser melhor, na região geográfica em tela. De fato, pela Figura 6, observa-se que a variedade Rubi Cabernet se estabeleceu lentamente, não flutuou quando houve extremos climáticos. Muito embora não tenha tido desempenho satisfatório, sob o ponto de vista da qualidade da uva e sob o ponto de vista da fenologia, a mesma conseguiu estabelecer reservas fisiológicas de forma lenta e não sofreu queda tão brusca quanto às outras variedades, devido ao impacto do cultivo sequencial.

Observando-se índices colorimétricos anotados na Tabela 8 , nota-se que os índices de intensidade de cor acompanham os níveis de antocianina, fato 
que é notório e pode ser observado em outros experimentos. De fato, Santos et al.(2008), em experimento com zoneamento da qualidade da uva, em campo, utilizaram três métodos diferentes de análise para a verificação da pigmentação fenólica em uva, onde se notou correlação positiva entre os métodos em si e entre estes e os índices colorimétricos. Portanto, pelos índices colorimétricos descritos na Tabela 8, pode-se inferir empiricamente sobre a pigmentação fenólica das duas primeiras safras. Baseados nestes dados descritores da qualidade da uva, assim como em todas as tabelas e gráficos descritores do desempenho das variedades durante as safras, pode-se concluir que a qualidade da produção aumentou do verão para o inverno.

Por outro lado, pelos dados da Tabela 9, depreende-se, da comparação entre os tratamentos submetidos à poda sequencial com parcelas que foram deixadas em "pousio" por um inverno, que ocorre um acúmulo menor de reservas nas parcelas submetidas à poda contínua. Ressalte-se que todas as parcelas, dentro de uma mesma safra, estiveram sempre submetidas às mesmas condições de física e fertilidade do solo, dentro do arranjo experimental adotado.
O fato descrito sugere que o cultivo de inverno na média altitude paulista deve ser feito com estrita observância à fertilidade do solo. Além da recomendação de rotação de "pousio", para uma mesma variedade, provavelmente, maiores espaçamentos de plantio devem favorecer o cultivo em dupla poda, pela possibilidade de se trabalhar com uma arquitetura de planta que favoreça alcançar melhor relação de fonte e dreno; na prática, busca-se manter níveis de reservas energéticas acumuladas em cada safra, que não encurte a vida útil da videira.

Como a alteração da época de poda parece não ter efeito significativo no aumento da qualidade da variedade americana estudada,e como para este tipo de vinho pequenas diferenças de qualidade não significam propriamente agregação de valor, pode-se inferir que para estas cultivares se deva optar por métodos de manejo visando ao aumento da rentabilidade da produção, como sistemas de condução e poda que privilegiem a mecanização, tanto da poda quanto da colheita, para empreendimentos empresariais, ou que privilegiem o aumento da produtividade, para empreendimentos familiares.

TABELA 1-Variáveis fenológicas e ecofisiológicas observadas em experimento com videira de suco e vinho, cultivada no verão e inverno, em Jundiaí-SP.

Safra de verão-2008 - (1 $\mathbf{1}^{\mathbf{a}}$ Poda $)$ - seguida da Safra de inverno-2009 - ( $\mathbf{2}^{\mathbf{a}}$ Poda $)$, safra de verão-2009- ( $3^{\mathbf{a}}$ Poda $)$ e safra de inverno-2010 - (4 $4^{\mathbf{a}}$ Poda $)$

\begin{tabular}{|c|c|c|c|c|c|}
\hline & $\begin{array}{l}\text { Total de chuva } \\
\text { poda - colheita } \\
\text { (mm) }\end{array}$ & $\begin{array}{c}\mathrm{ETr} \\
\text { poda }- \text { colheita } \\
(\mathrm{mm})\end{array}$ & $\begin{array}{c}\text { Soma Térmica } \\
\text { (Graus-dia) } \\
\left({ }^{\circ} \mathrm{C}\right)\end{array}$ & $\begin{array}{l}\mathrm{N}^{\circ} \text { Dias com } \\
\text { chuva } \geq 5 \mathrm{~mm}\end{array}$ & $\begin{array}{l}\text { Mínino Potencial da } \\
\text { água na folha pós- } \\
\text { floração* (MPa) }\end{array}$ \\
\hline Evento & & & Isabel & & \\
\hline $1^{\text {a }}$ Poda & 606,80 & 328,87 & 1470,33 & 50 & - \\
\hline $2^{\mathrm{a}}$ Poda & 335,0 & 299,03 & 1242,15 & 37 & $-1,3$ \\
\hline $3^{\text {a }}$ Poda & 794,0 & 358,35 & 1543,08 & 62 & $-1,0$ \\
\hline \multirow[t]{2}{*}{$4^{\mathrm{a}}$ Poda } & 345,70 & 273,43 & 1131,52 & 32 & $-1,3$ \\
\hline & & & IAC-Máximo & & \\
\hline $1^{\text {a }}$ Poda & 536,40 & 299,31 & 1363,03 & 43 & - \\
\hline $2^{\mathrm{a}}$ Poda & 300,40 & 281,39 & 1174,39 & 34 & $-1,3$ \\
\hline $3^{\text {a }}$ Poda & 776,30 & 341,50 & 1479,67 & 59 & $-1,0$ \\
\hline \multirow[t]{2}{*}{$4^{\mathrm{a}}$ Poda } & 345,30 & 267,01 & 1098,09 & 20 & $-1,3$ \\
\hline & & & Rubi-Caberne & & \\
\hline $1^{\mathrm{a}}$ Poda & 679,40 & 370,75 & 1625,44 & 56 & - \\
\hline $2^{\mathrm{a}}$ Poda & - & - & - & - & $-1,4$ \\
\hline $3^{\text {a }}$ Poda & 907,40 & 397,78 & 1687,61 & 74 & $-1,0$ \\
\hline $4^{\mathrm{a}}$ Poda & 333,0 & 305,39 & 1339,77 & 33 & $-1,3$ \\
\hline
\end{tabular}


TABELA 2-Médias dos tratamentos para peso de cachos, em experimento com videira de suco e vinho, em Jundiaí -SP

\begin{tabular}{|c|c|c|c|c|c|}
\hline \multicolumn{6}{|c|}{$\begin{array}{c}\left.\text { Safra de Verão (2008- } \text { a }^{\mathrm{a}} \text { Poda }\right) \text { - seguida das safras de inverno }\left(2009-2^{\mathrm{a}} \text { Poda }\right) \\
\text { verão }\left(2009-3^{\mathrm{a}} \text { poda }\right) \text { e Inverno }\left(2010-4^{\mathrm{a}} \text { poda }\right)\end{array}$} \\
\hline \multirow{2}{*}{\multicolumn{2}{|c|}{ Cultivar }} & \multicolumn{4}{|c|}{ Peso de cachos (g) } \\
\hline & & $1^{\mathrm{a}}$ Poda & $2^{\mathrm{a}}$ Poda & $3^{\mathrm{a}}$ Poda & $4^{\mathrm{a}}$ Poda \\
\hline \multirow{4}{*}{ 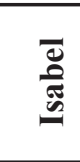 } & 766 & 133,62 & $91,62^{*}$ & 112,4 & 67,41 \\
\hline & $T R A$ & $132,64^{*}$ & 110,65 & 115,6 & $60,45^{*}$ \\
\hline & 572 & 140,84 & $132,42 *$ & $98,65^{*}$ & 88,01 \\
\hline & $\mathrm{SO} 4$ & $141,10^{*}$ & 98,65 & $135,3^{*}$ & $91,81 *$ \\
\hline \multirow{6}{*}{ 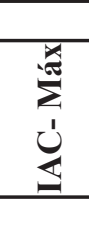 } & Med & $a$ & $a$ & $a$ & $b$ \\
\hline & 766 & 98,75 & 107,98 & 84,41 & $72,48^{*}$ \\
\hline & $T R A$ & $132,38^{*}$ & 98,65 & $95,63 *$ & 71,46 \\
\hline & 572 & 123,37 & $110,12 *$ & 78,69 & $69,47 *$ \\
\hline & $\mathrm{SO} 4$ & $95,78^{*}$ & $87,65^{*}$ & $77,14^{*}$ & 71,96 \\
\hline & Med & $a$ & $a$ & $b$ & $b$ \\
\hline \multirow{5}{*}{ 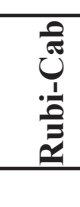 } & 766 & $66,79^{*}$ & & 100,2 & $104,7^{*}$ \\
\hline & $T R A$ & 78,93 & & 99,56 & 98,70 \\
\hline & 572 & $93,62 *$ & & $101,3^{*}$ & 97,65 \\
\hline & $\mathrm{SO} 4$ & 88,32 & & $97,61^{*}$ & $95,87 *$ \\
\hline & Med & $a$ & & $b$ & $b$ \\
\hline
\end{tabular}

[766= IAC 766-Campinas; 572 = IAC 572-Jales; TRA = Ripária do Traviú]

Na mesma coluna, grupos com o mesmo simbolo diferem significativamente entre si (anova/tukey P<0,005); entre colunas, média de grupos com a mesma letra não difere significativamente entre si, de uma poda para outra, $P<0,05$

TABELA 3- Médias dos tratamentos para peso de baga, em experimento com videira de suco e vinho, em Jundiaí-SP.

\begin{tabular}{|c|c|c|c|c|c|}
\hline \multicolumn{6}{|c|}{$\begin{array}{c}\left.\text { Safra de Verão (2008- } \text { 1 }^{\mathrm{a}} \text { Poda }\right) \text { - seguida das safras de inverno }\left(2009-2^{\mathrm{a}} \text { Poda }\right) \\
\text { verão }\left(2009-3^{\mathrm{a}} \text { poda }\right) \text { e Inverno }\left(2010-4^{\mathrm{a}} \text { poda }\right)\end{array}$} \\
\hline \multirow[t]{2}{*}{ Cultivar } & & \multicolumn{4}{|c|}{ Peso de bagas (g) } \\
\hline & & $1^{\text {a }}$ Poda & $2^{\mathrm{a}}$ Poda & $3^{\mathrm{a}}$ Poda & $4^{\mathrm{a}}$ Poda \\
\hline \multirow{4}{*}{ 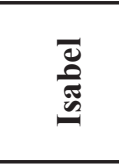 } & 766 & $2,68^{*}$ & $2,91^{*}$ & $2,18^{*}$ & $2,28^{*}$ \\
\hline & $T R A$ & 2,93 & 2,65 & 2,86 & 2,45 \\
\hline & 572 & $3,18^{*}$ & 2,85 & 2,49 & 2,95 \\
\hline & SO4 & 2,93 & $2,25^{*}$ & $3,15^{*}$ & $3,10^{*}$ \\
\hline & Med & $a$ & $a$ & $a$ & $a$ \\
\hline \multirow{5}{*}{ 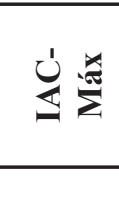 } & 766 & 1,59 & 1,44 & 1,41 & $1,35^{*}$ \\
\hline & $T R A$ & $1,65^{*}$ & $1,33^{*}$ & $1,58^{*}$ & 1,40 \\
\hline & 572 & 1,56 & $1,50 *$ & 1,56 & 1,36 \\
\hline & SO4 & $1,56^{*}$ & 1,44 & $1,36^{*}$ & $1,42 *$ \\
\hline & Med & $a$ & $b$ & $b$ & $b$ \\
\hline \multirow{5}{*}{ U } & 766 & 1,77 & & $1,85^{*}$ & $1,70^{*}$ \\
\hline & $T R A$ & 1,79 & & 1,79 & 1,69 \\
\hline & 572 & 1,77 & & 1,77 & 1,67 \\
\hline & SO4 & 1,70 & & $1,65^{*}$ & $1,55^{*}$ \\
\hline & Med & $\mathbf{a}$ & & $a$ & $a$ \\
\hline
\end{tabular}

[766= IAC 766-Campinas; 572 = IAC 572-Jales; Tra = Ripária do Traviú]

Na mesma coluna, grupos com o mesmo simbolodiferem significativamente entre si (anova/tukey $P<0,005)$; entre colunas, média de grupos com a mesma letra não difere significativamente entre si, de uma poda para outra, $P<0,05$ 
TABELA 4 - Médias dos tratamentos para $n^{\circ}$ de cachos/ramo, em experimento com videira de suco e vinho, em Jundiaí-SP

Safra de Verão (2008- 1 ${ }^{\mathrm{a}}$ Poda) - seguida das safras de inverno (2009 - 2a Poda ), verão $\left(2009-3^{\mathrm{a}}\right.$ poda $)$ e Inverno $\left(2010-4^{\mathrm{a}}\right.$ poda $)$

\begin{tabular}{|c|c|c|c|c|c|}
\hline \multicolumn{2}{|c|}{ Cultivar } & \multicolumn{4}{|c|}{$\mathrm{N}^{0}$ de cachos/ramo } \\
\hline \multirow{5}{*}{ 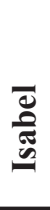 } & & $1^{\mathrm{a}}$ Poda & $2^{\mathrm{a}}$ Poda & $3^{\mathrm{a}}$ Poda & $4^{\mathrm{a}}$ Poda \\
\hline & 766 & $2,87^{*}$ & 2,00 & 1,90 & 1,65 \\
\hline & $T R A$ & 2,70 & $2,10^{*}$ & $2,10^{*}$ & 1,60 \\
\hline & 572 & 2,75 & 1,85 & $1,65^{*}$ & $1,50 *$ \\
\hline & $\mathrm{SO4}$ & $2,62 *$ & $1,82 *$ & 1,95 & $1,75^{*}$ \\
\hline \multirow{6}{*}{ 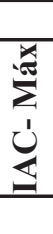 } & Med & $a$ & $b$ & $b c$ & $c$ \\
\hline & 766 & $3,30^{*}$ & $2,20 *$ & 2,2 & 1,9 \\
\hline & $T R A$ & 3,00 & $2,50^{*}$ & 2,1 & 1,9 \\
\hline & 572 & $2,50 *$ & 2,25 & $2,0^{*}$ & 1,8 \\
\hline & $\mathrm{SO} 4$ & 2,63 & 2,25 & $2,5^{*}$ & 1,8 \\
\hline & $\mathrm{Med}$ & $a$ & $b$ & $b c$ & $c$ \\
\hline \multirow{5}{*}{ 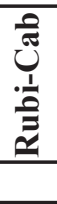 } & 766 & $1,75^{*}$ & $1,80^{*}$ & $1,7^{*}$ & $1,5^{*}$ \\
\hline & $T R A$ & $2,25^{*}$ & 1,70 & 1,6 & 1,5 \\
\hline & 572 & 1,87 & 1,45 & 1,6 & $1,25^{*}$ \\
\hline & $\mathrm{SO} 4$ & 1,87 & $1,35^{*}$ & $1,5^{*}$ & 1,3 \\
\hline & Med & $a$ & $b$ & $a b$ & $b$ \\
\hline
\end{tabular}

[766= IAC 766-Campinas; 572 = IAC 572-Jales; Tra = Ripária do Traviú]

Na mesma coluna, grupos com o mesmo símbolo diferem significativamente entre si (anova/tukey $\mathrm{P}<0,005$ ); entre colunas, média de grupos com a mesma letra não difere significativamente entre si, de uma poda para outra, $\mathrm{P}<0,05$

TABELA 5- Médias dos tratamentos para produção/planta, em experimento com videira de suco e vinho, em Jundiaí- SP.

Safra de Verão (2008- $1^{\mathrm{a}}$ Poda) - seguida das safras de inverno (2009 - $2^{\mathrm{a}}$ Poda $)$, verão $\left(2009-3^{\mathrm{a}}\right.$ poda) e Inverno $\left(2010-4^{\mathrm{a}}\right.$ poda $)$

\begin{tabular}{|c|c|c|c|c|c|}
\hline \multicolumn{2}{|c|}{ Cultivar } & \multicolumn{4}{|c|}{ Produção/planta (kg) } \\
\hline \multirow{5}{*}{$\begin{array}{l}\bar{D} \\
\bar{E} \\
\mathscr{E}\end{array}$} & & $1^{\mathrm{a}}$ Poda & $2^{\mathrm{a}}$ Poda & $3^{\text {a }}$ Poda & $4^{\mathrm{a}}$ Poda \\
\hline & 766 & $3,45^{*}$ & 3,20 & 3,15 & 2,96 \\
\hline & TRA & 3,37 & $3,29 *$ & $3,45^{*}$ & 2,84 \\
\hline & 572 & $2,40 *$ & 2,39 & $2,95^{*}$ & $2,76^{*}$ \\
\hline & $\mathrm{SO} 4$ & 2,92 & $2,28^{*}$ & 3,35 & $3,10^{*}$ \\
\hline \multirow{5}{*}{$\underbrace{2}$} & & a & a & $a$ & $a$ \\
\hline & 766 & 2,00 & 1,943 & $3,58^{*}$ & $3,49^{*}$ \\
\hline & TRA & 2,15 & 1,982 & 3,45 & $2,25^{*}$ \\
\hline & 572 & $3,32 *$ & $2,12^{*}$ & $2,95^{*}$ & 2,35 \\
\hline & $\mathrm{SO} 4$ & $1,37 *$ & $1,87^{*}$ & 3,16 & 2.48 \\
\hline \multirow{6}{*}{$\overline{\underline{\underline{E}}}$} & & $a$ & a & $b$ & $a b$ \\
\hline & 766 & 1,53 & & 2,10 & $2,50 *$ \\
\hline & TRA & 1,52 & & $1,95 *$ & $1,85^{*}$ \\
\hline & 572 & 1,31 & & 2,07 & 2,12 \\
\hline & $\mathrm{SO} 4$ & 1,50 & & $2,15^{*}$ & 1,90 \\
\hline & & $a$ & & $b$ & $b$ \\
\hline
\end{tabular}

Na mesma coluna, grupos com o mesmo símbolo diferem significativamente entre si (anova/tukey $\mathrm{P}<0,005$ ); entre colunas, média de grupos com a mesma letra não difere significativamente entre si, de uma poda para outra, $\mathrm{P}<0,05$ 
TABELA 6 - Médias do tratamentos para o material podado, em experimento com videira de suco e vinho, em Jundiaí-SP.

Safra de Verão (2008- $1^{\text {a }}$ Poda) - seguida das safras de inverno (2009 - $2^{\mathrm{a}}$ Poda $)$, verão (2009 - $3^{\mathrm{a}}$ poda) e Inverno (2010 - $4^{\mathrm{a}}$ poda)

\begin{tabular}{|c|c|c|c|c|c|}
\hline \multirow[t]{2}{*}{ Cultivar } & & \multicolumn{4}{|c|}{ Peso médio de ramos (g) } \\
\hline & & $1^{\text {a }}$ Poda & $2^{\mathrm{a}}$ Poda & $3^{\mathrm{a}}$ Poda & $4^{\mathrm{a}}$ Poda \\
\hline \multirow{4}{*}{$\begin{array}{l}\vec{\Phi} \\
\stackrel{\Xi}{\tilde{E}} \\
=\end{array}$} & 766 & 25,19 & $28,5^{*}$ & $56,23 *$ & 12,28 \\
\hline & $T R A$ & $26,62 *$ & 20,9 & 40,73 & $15,53 *$ \\
\hline & 572 & $17,64 *$ & 22,44 & 52,65 & 12,47 \\
\hline & $\mathrm{SO} 4$ & 17,69 & $15,53^{*}$ & $34,37 *$ & $11,84^{*}$ \\
\hline \multirow{6}{*}{ 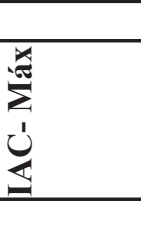 } & & $a$ & $a$ & $b$ & $c$ \\
\hline & 766 & 19,6 & 27,44 & $37,84^{*}$ & $11,22 *$ \\
\hline & $T R A$ & $20,89^{*}$ & $30,29 *$ & 27,80 & 9,70 \\
\hline & 572 & $13,43^{*}$ & $17,73^{*}$ & 28,12 & 10,75 \\
\hline & $\mathrm{SO} 4$ & 14,52 & 20,04 & $26,54 *$ & $8,94 *$ \\
\hline & & $a$ & $a b$ & $b$ & $c$ \\
\hline \multirow{5}{*}{ 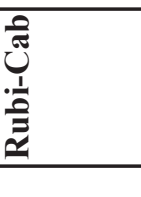 } & 766 & 21,4 & 29,1 & 39,33 & $39,37^{*}$ \\
\hline & $T R A$ & $25,56^{*}$ & $35,63^{*}$ & $44,50^{*}$ & 36,72 \\
\hline & 572 & 20 & 31,04 & 25,76 & 35,02 \\
\hline & SO4 & $16,3^{*}$ & $21,16^{*}$ & $23,37^{*}$ & $32,09 *$ \\
\hline & & $a$ & $a b$ & $a b$ & $b$ \\
\hline
\end{tabular}

[766= IAC 766-Campinas; 572 = IAC 572-Jales; Tra = Ripária do Traviú]

Na mesma coluna, grupos com o mesmo simbolodiferem significativamente entre si (anova/tukey P<0,005); entre colunas, média de grupos com a mesma letranão diferesignificativamente entre si, de uma poda para outra, $P<0,05$

TABELA 7 - Variáveis fenológicas e ecofisiológicas observados em experimento com videira de suco e vinho, cultivada no verão e inverno, em Jundiaí-SP.

Safra de verão-2008 - (1 $\mathbf{1}^{\mathbf{a}}$ Poda) - seguida da Safra de inverno-2009 -

( $2^{\mathbf{a}}$ Poda $)$, safra de verão-2009- ( $3^{\mathbf{a}}$ Poda $)$ e safra de inverno-2010 - (4 $4^{\mathbf{a}}$ Poda)

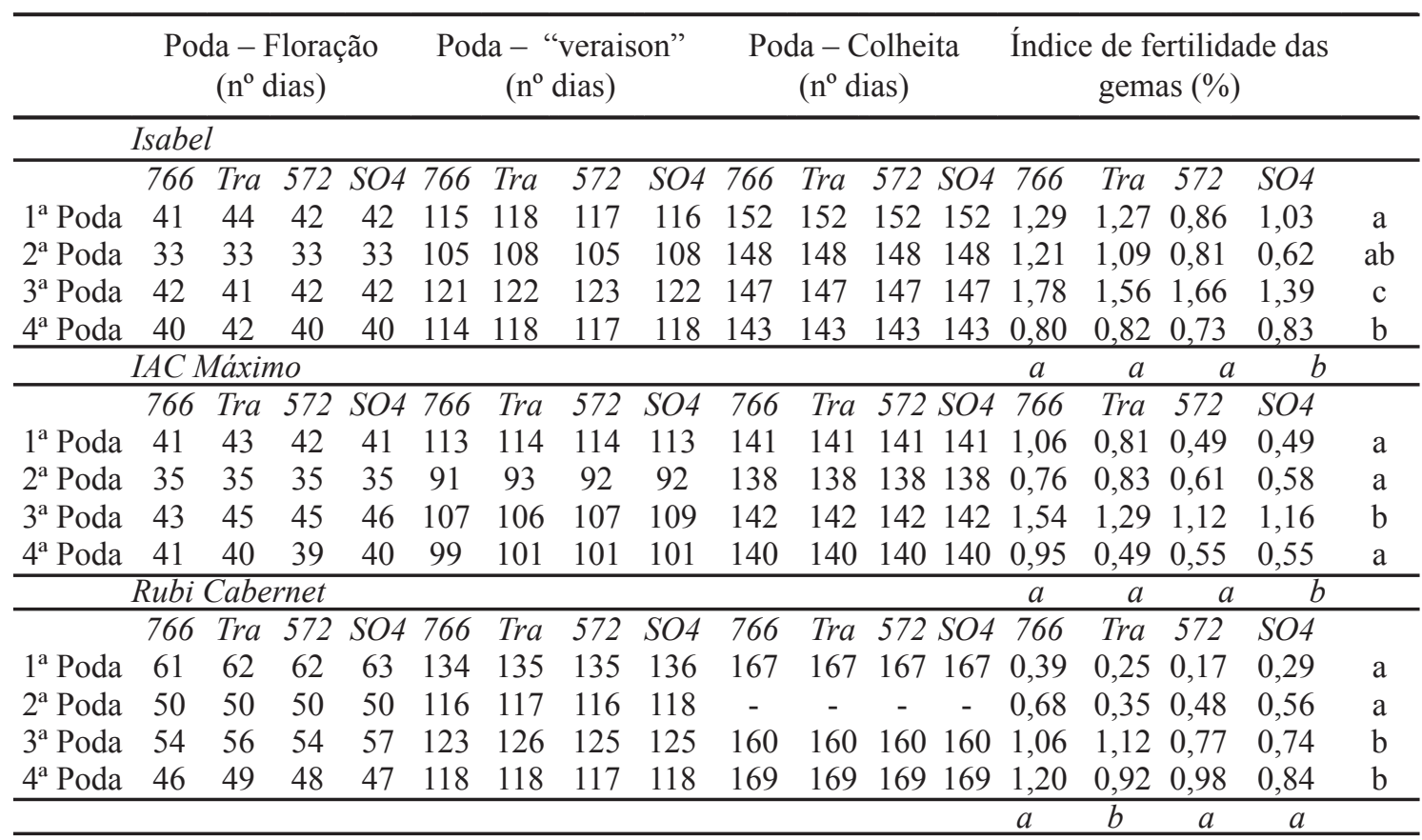

Para Fertilidade das gemas ,a média de grupos com a mesma letra não difere significativamente entre si, de uma época de poda para outra, ou dentro da mesma época de poda (anova/tukey $\mathrm{P}<0,005$ ).

[766= IAC 766-Campinas; IAC 572-Jales; Tra=Ripária do Traviú] 
TABELA 8 - Médias dos tratamentos para indicadores da qualidade do mosto de uva, obtidos em experimento com videira de suco e vinho, em São Paulo, no período de 2008 a 2010.

Safra de verão-2008 - (1 $\mathbf{1}^{\mathbf{a}}$ Poda $)$ - seguida da Safra de inverno-2009 - ( $\mathbf{2}^{\mathbf{a}}$ Poda $)$, safra de verão-2009- ( $3^{\mathbf{a}}$ Poda) e safra de inverno-2010 - (4 $4^{\mathbf{a}}$ Poda $)$

\section{Coloração}

$\begin{array}{cccccc}\text { Mosto Descuba: } & \text { Mosto } & \text { Antocianina } & & & \\ \text { D520+A420 } & \text { Descuba: } & \text { (Malvidina-3- } & \text { Polifenóis Totais } & \text { Tanino } & \\ \text { (Intensidade) } & \text { A520/A420 } & \text { glicosídeo }) & \text { (UA/g) } & \text { (UAix } \\ \text { (Tonalidade) } & (\mathrm{mg} / \mathrm{g}) & & & \end{array}$

\begin{tabular}{|c|c|c|c|c|c|c|c|}
\hline \multirow[t]{2}{*}{ Poda } & \multirow{2}{*}{$\frac{\text { p.e. }}{766}$} & \multicolumn{6}{|c|}{ Isabel } \\
\hline & & 1,4560 & 0,7333 & - & - & - & 18,6 \\
\hline & TRA & 0,7480 & 0,6961 & - & - & - & 16,2 \\
\hline \multirow[t]{4}{*}{$1^{\mathrm{a}}$ Poda } & 572 & 0,4200 & 0,5273 & - & - & - & 16,4 \\
\hline & $\mathrm{SO} 4$ & 1,2180 & 0,7475 & - & - & - & 18,0 \\
\hline & 766 & 0,6650 & 0,458 & - & - & - & 17,4 \\
\hline & TRA & 0,975 & 0,712 & - & - & - & 16,8 \\
\hline \multirow[t]{4}{*}{$2^{\mathrm{a}}$ Poda } & 572 & 1,215 & 0,623 & - & - & - & 17,0 \\
\hline & $\mathrm{SO} 4$ & 1,356 & 0,815 & - & - & - & 17,8 \\
\hline & 766 & 1,360 & 0,586 & 0,813 & 0,693 & 2,09 & 15,6 \\
\hline & TRA & 0,980 & 0,612 & 1,088 & 0,817 & 2,574 & 15,0 \\
\hline \multirow[t]{4}{*}{$3^{\mathrm{a}}$ Poda } & 572 & 0,960 & 0,712 & 0,704 & 0,608 & 1,034 & 15,0 \\
\hline & $\mathrm{SO} 4$ & 0,850 & 0,452 & 1,264 & 0,884 & 1,727 & 16 \\
\hline & 766 & 1,420 & 0,597 & 1,026 & 1,063 & 3,11 & 16,0 \\
\hline & TRA & 1,023 & 0,690 & 1,515 & 1,155 & 1,70 & 15,6 \\
\hline \multirow[t]{5}{*}{$4^{\mathrm{a}}$ Poda } & 572 & 0,901 & 0,680 & 0,631 & 0,716 & 1,70 & 16,0 \\
\hline & $\mathrm{SO} 4$ & 0,680 & 0,523 & 0,855 & 0,959 & 3,40 & 16,2 \\
\hline & p.e. & & & & & & \\
\hline & 766 & 1,763 & 0,3731 & - & - & - & 18,0 \\
\hline & TRA & 1,341 & 0,4101 & - & - & - & 14,6 \\
\hline \multirow[t]{4}{*}{$1^{\mathrm{a}}$ Poda } & 572 & 1,594 & 0,4245 & - & - & - & 16,0 \\
\hline & $\mathrm{SO} 4$ & 1,698 & 0,3895 & - & - & - & 15,0 \\
\hline & 766 & 1,852 & 0,512 & - & - & - & 17,0 \\
\hline & TRA & 1,652 & 0,498 & - & - & - & 16,0 \\
\hline \multirow[t]{4}{*}{$2^{\mathrm{a}}$ Poda } & 572 & 1,745 & 0,658 & - & - & - & 18,0 \\
\hline & $\mathrm{SO} 4$ & 1,854 & 0,489 & - & - & - & 17,8 \\
\hline & 766 & 1,630 & 0,689 & 2,622 & 1,611 & 3,201 & 15,0 \\
\hline & TRA & 1,714 & 0,654 & 3,017 & 2,012 & 1,276 & 15,2 \\
\hline \multirow[t]{4}{*}{$3^{\mathrm{a}}$ Poda } & 572 & 1,550 & 0,678 & 2,377 & 1,461 & 3,707 & 15,6 \\
\hline & $\mathrm{SO} 4$ & 1,120 & 0,667 & 2,132 & 1,327 & 3,641 & 15,4 \\
\hline & 766 & 1,996 & 0,715 & 3,030 & 1,698 & 4,80 & 15,4 \\
\hline & TRA & 1,865 & 0,698 & 3,220 & 1,965 & 4,70 & 16,0 \\
\hline \multirow[t]{2}{*}{$4^{\mathrm{a}}$ Poda } & 572 & 1,623 & 0,715 & 2,920 & 1,580 & 4,65 & 15,2 \\
\hline & $\mathrm{SO} 4$ & 1,635 & 0,750 & 2,990 & 1,541 & 4,75 & 16,0 \\
\hline
\end{tabular}




\begin{tabular}{|c|c|c|c|c|c|c|c|}
\hline & p.e. & & & $R u b$ & & & \\
\hline & 766 & 0,6760 & 0,4475 & - & - & - & 12,2 \\
\hline & TRA & 0,712 & 0,563 & - & - & - & 11,6 \\
\hline $1^{\text {a }}$ Poda & 572 & 0,813 & 0,498 & - & - & - & 12,2 \\
\hline & SO4 & 0,413 & 0,325 & - & - & - & 13,0 \\
\hline & 766 & - & - & - & - & - & - \\
\hline & TRA & - & - & - & - & - & - \\
\hline $2^{\mathrm{a}}$ Poda & 572 & - & - & - & - & - & - \\
\hline & SO4 & - & - & - & - & - & - \\
\hline & 766 & 0,530 & 0,325 & 1,432 & 1,339 & 6,941 & 11,0 \\
\hline & TRA & 0,712 & 0,489 & 1,340 & 1,259 & 6,71 & 12,0 \\
\hline $3^{\mathrm{a}}$ Poda & 572 & 0,850 & 0,652 & 1,363 & 1,178 & 6,171 & 13,0 \\
\hline & $\mathrm{SO} 4$ & 0,754 & 0,712 & 1,617 & 1,448 & 7,183 & 12,2 \\
\hline & 766 & 0,967 & 0,398 & 2,564 & 1,571 & 5,30 & 12,2 \\
\hline & TRA & 0,794 & 0,587 & 2,480 & 1,480 & 5,28 & 13,0 \\
\hline $4^{\mathrm{a}}$ Poda & 572 & 0,974 & 0,745 & 2,360 & 1,620 & 5,30 & 13,2 \\
\hline & $\mathrm{SO} 4$ & 0,800 & 0,798 & 2,590 & 1,490 & 5,96 & 13,0 \\
\hline
\end{tabular}

[766= IAC 766-Campinas; 572 = IAC 572-Jales; Tra = Ripária do Traviú; p.e.= porta-enxerto]

TABELA 9-Médias dos tratamentos para acúmulo de reservas em ramos, em experimento com videira de suco e vinho, em Jundiaí-SP

Safra de Inverno (2010)

Peso médio de ramos (g), encontrados após quatro estações de crescimento

\begin{tabular}{|c|c|c|c|c|c|}
\hline \multirow{2}{*}{\multicolumn{2}{|c|}{ Cultivar }} & \multicolumn{2}{|c|}{$\begin{array}{l}\text { Variedade com pousio em um inverno } \\
\text { (três podas) }\end{array}$} & \multicolumn{2}{|c|}{$\begin{array}{l}\text { Variedade sem pousio no inverno } \\
\text { (quatro podas) }\end{array}$} \\
\hline & & $1^{\text {a }}$ Poda & $4^{\mathrm{a}}$ poda & $1^{\mathrm{a}}$ Poda & $4^{\mathrm{a}}$ poda \\
\hline \multirow{5}{*}{ Isabel } & 766 & 27,0 & $41,21^{*}$ & 25,19 & 12,28 \\
\hline & $T R A$ & $31,82 *$ & 30,94 & $26,62 *$ & $15,53^{*}$ \\
\hline & 572 & $22,0^{*}$ & 34,50 & $17,64 *$ & 12,47 \\
\hline & $\mathrm{SO} 4$ & 22,07 & $24,16^{*}$ & 17,69 & $11,84 *$ \\
\hline & Média & $25,72 a$ & $32,70 a$ & $21,79 a$ & $13,03 \mathrm{~b}$ \\
\hline \multirow{5}{*}{ IAC- Máximo } & 766 & 20,74 & $22,86^{*}$ & 19,6 & $11,22 *$ \\
\hline & $T R A$ & $22,83^{*}$ & 16,00 & $20,89 *$ & 9,70 \\
\hline & 572 & $15,33^{*}$ & 16,47 & $13,43^{*}$ & 10,75 \\
\hline & $\mathrm{SO4}$ & 16,92 & $12,5^{*}$ & 14,52 & $8,94 *$ \\
\hline & Média & $18,96 a$ & $16,98 a$ & $17,11 a$ & $10,15 b$ \\
\hline
\end{tabular}

[766= IAC 766-Campinas; 572 = IAC 572-Jales; Trav = Ripária do Traviú $]$

Na mesma coluna, grupos com o mesmo símbolo diferem significativamente entre si (anova/tukey $\mathrm{P}<0,005$ ); entre colunas, média de grupos com a mesma letra não difere significativamente entre si, de uma poda para outra, $\mathrm{P}<0,05$ 


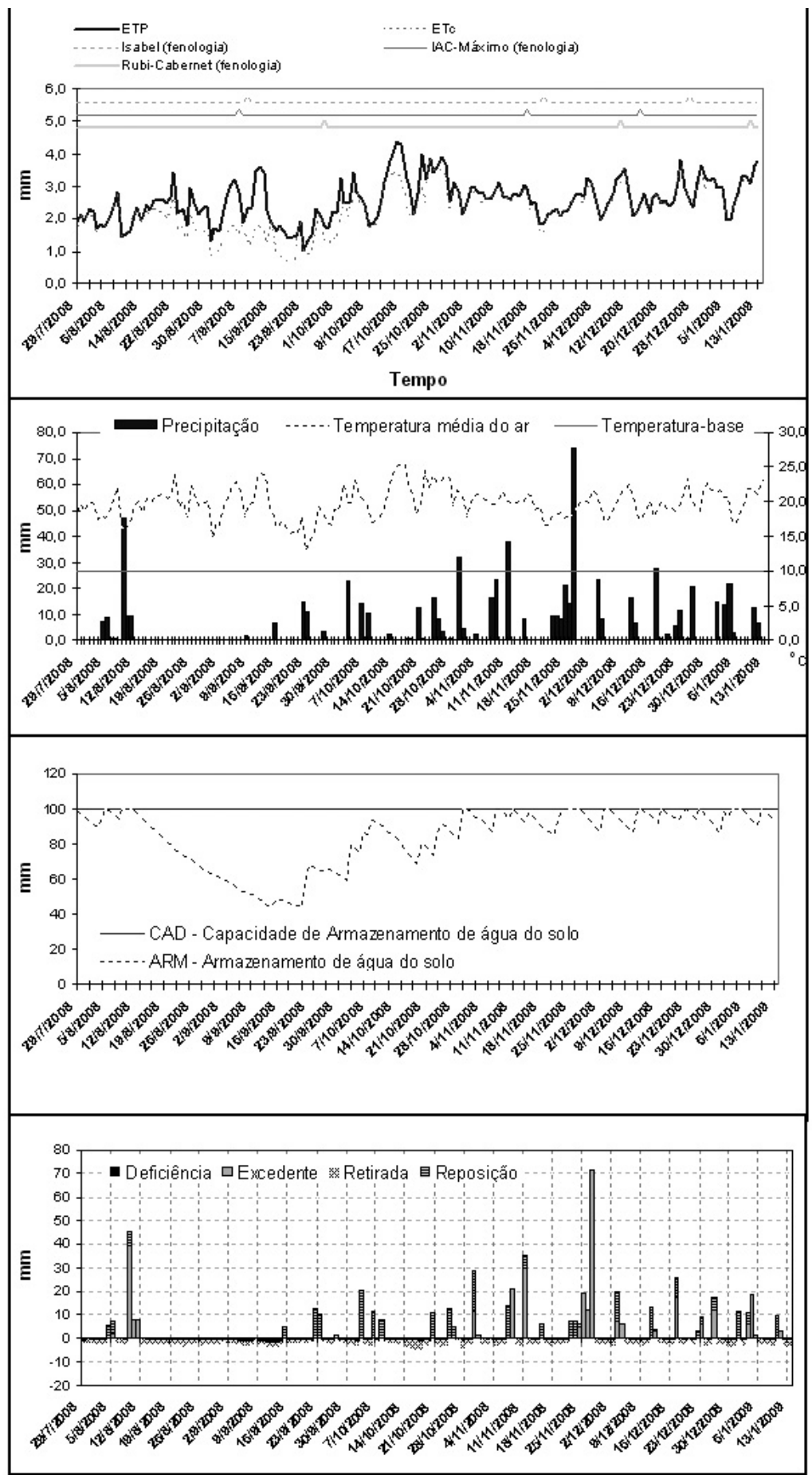

FIGURA 1 - Condições microclimáticas e da dinâmica da água no solo incidentes em área de experimento com uva de suco e vinho, colhidas no verão de 2009 ( $1^{\text {a }}$ estação de produção), em Jundía- SP. Ressaltos na curva de fenologia das variedades indicam a sequência de floração, "verasion" e colheita 


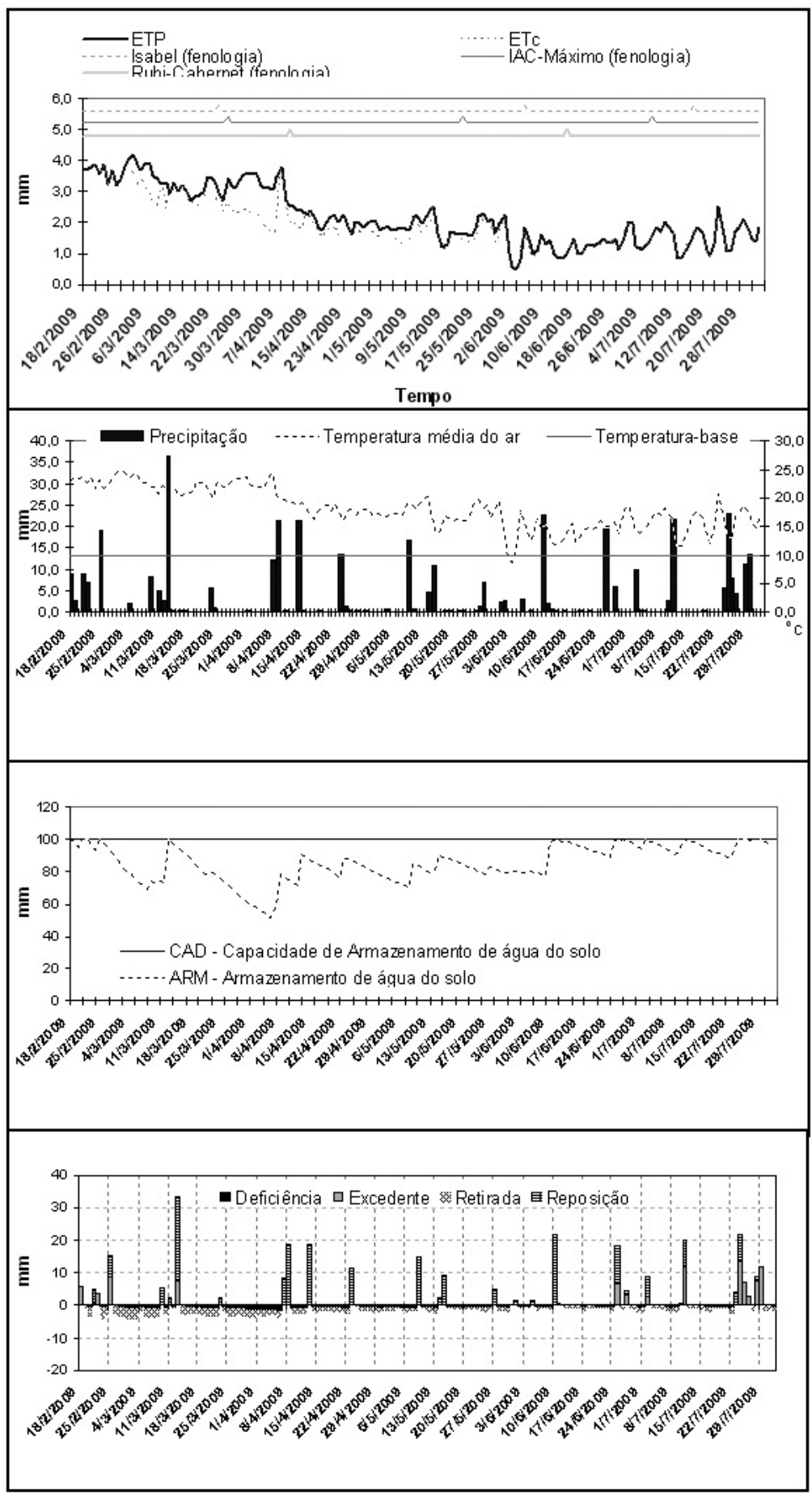

FIGURA 2 - Condições microclimáticas e da dinâmica da água no solo incidentes em área de experimento com uva de suco e vinho, colhidas no inverno de 2009 ( $2^{\mathrm{a}}$ estação de produção), em Jundiaí-SP. Ressaltos na curva de fenologia das variedades indicam a sequência de floração, "veraison" e colheita. 


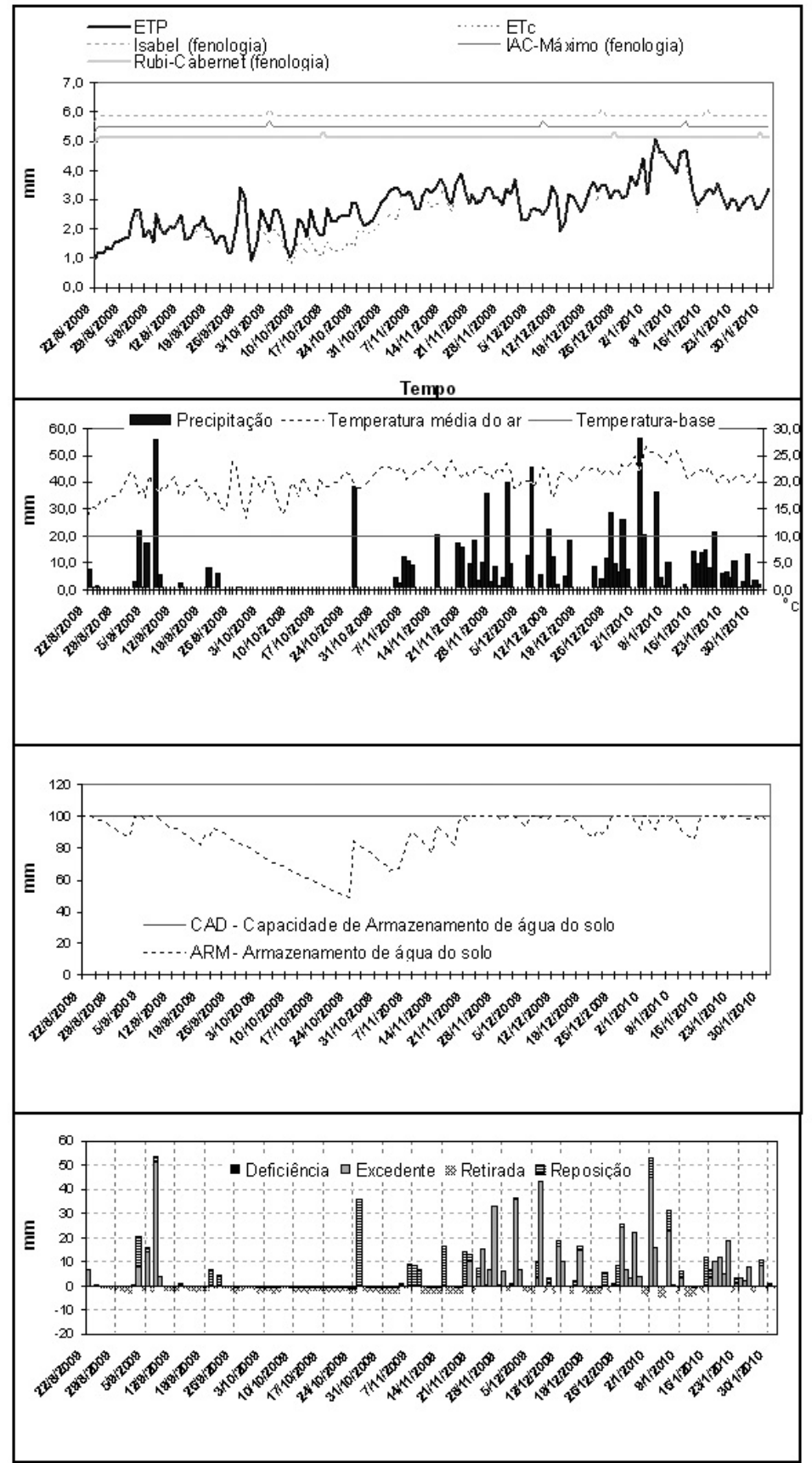

FIGURA 3 - Condições microclimáticas e da dinâmica da água no solo incidentes em área de experimento com uva de suco e vinho, colhidas no verão de 2010 ( $3^{\text {a }}$ estação de produção), em Jundiaí-SP. Ressaltos na curva de fenologia das variedades indicam a sequência de floração, "verasion" e colheita. 


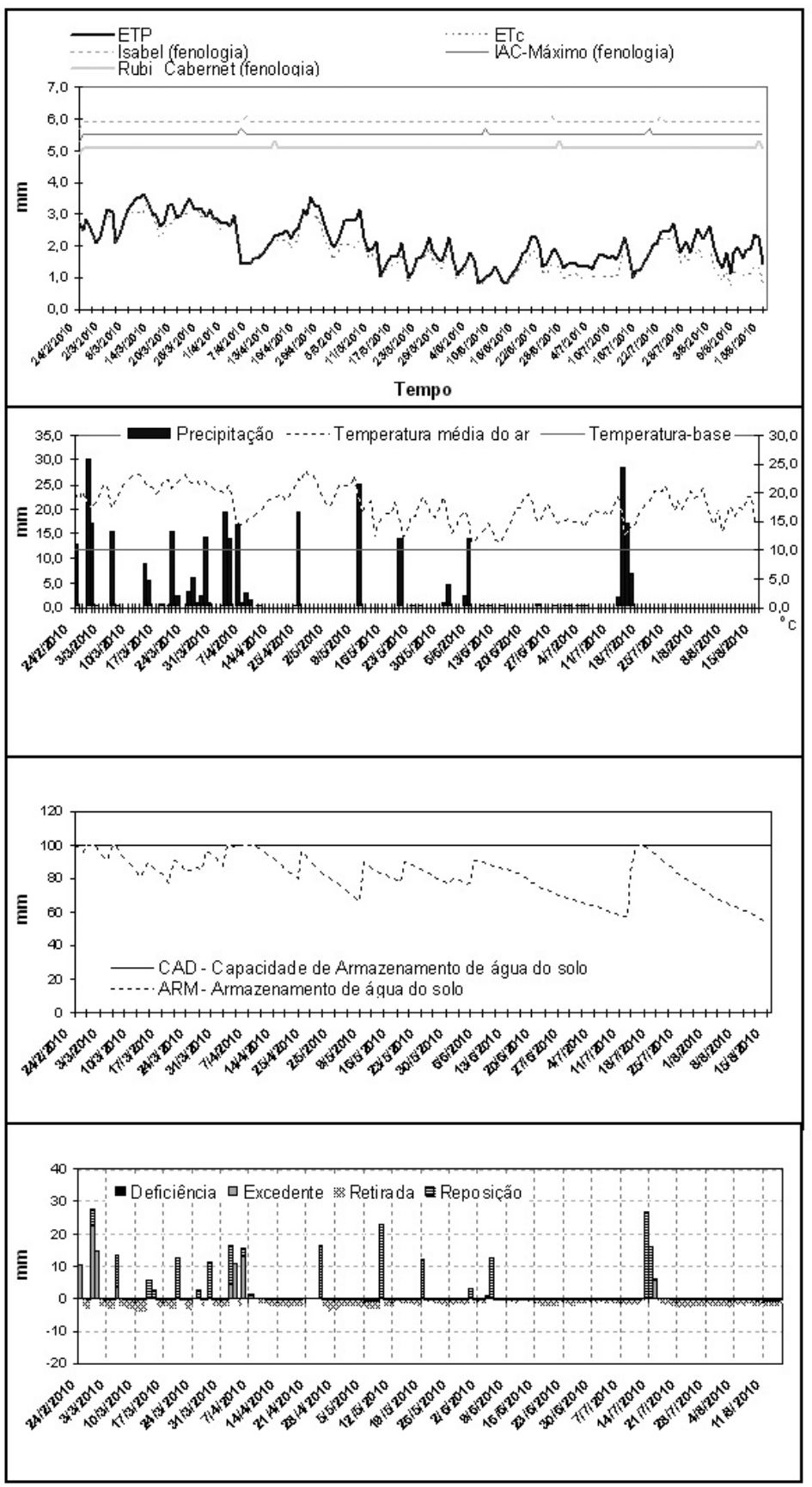

FIGURA 4- Condições microclimáticas e da dinâmica da água no solo incidentes em área de experimento com uva de suco e vinho, colhidas no inverno de 2010 ( $4^{a}$ estação de produção), em Jundiaí-SP. Ressaltos na curva de fenologia das variedades indicam a sequência de floração, "verasion" e colheita. 


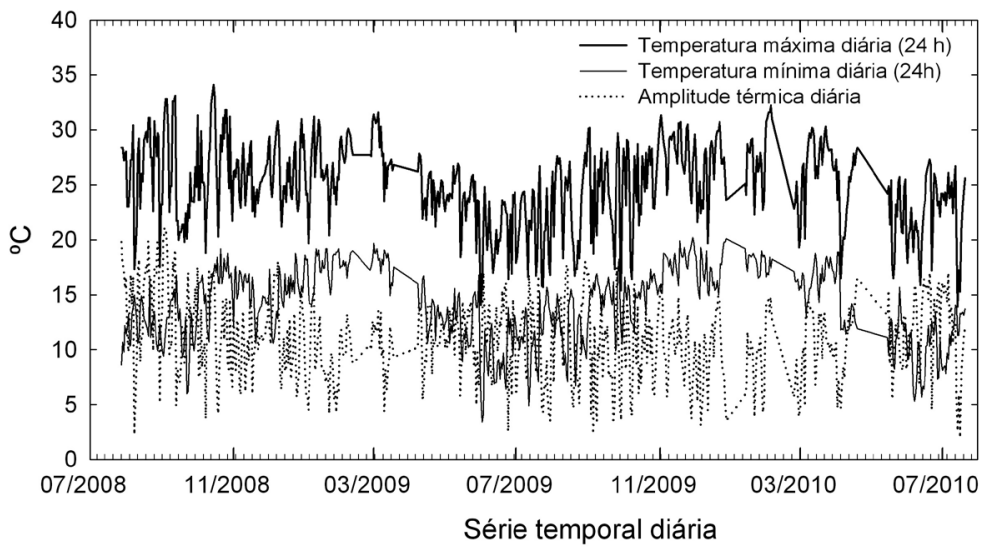

FIGURA 5 - Evolução da marcha diária da temperatura máxima, mínima e da amplitude térmica, em experimento com a videira de suco e vinho em Jundiaí-SP, no período de 2008 a 2010.
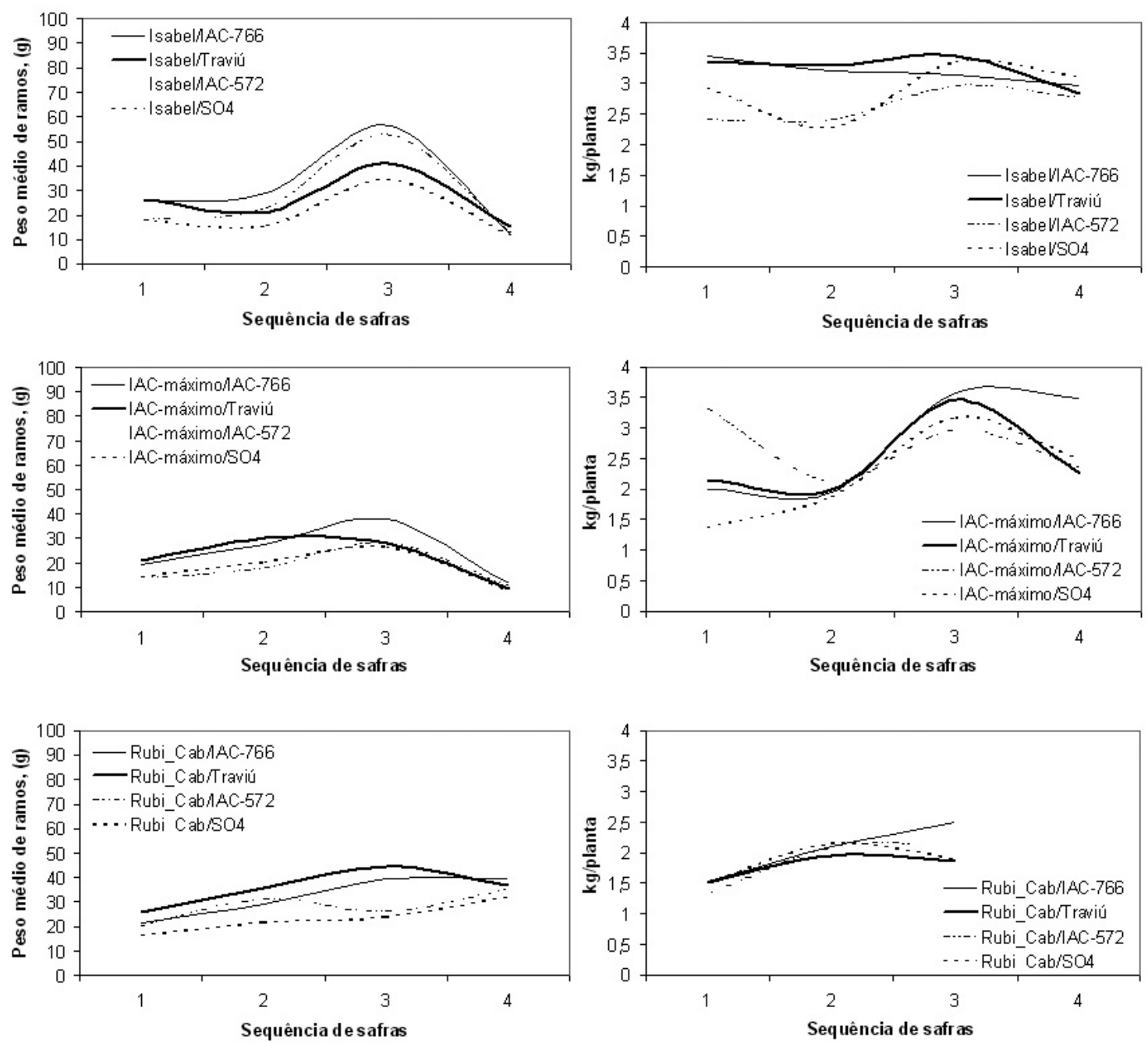

FIGURA 6 - Evolução do peso médio de ramos (nível de reservas) e produtividade média, separadamente por porta-enxerto, em experimento com a videira de suco e vinho, cultivada em sequência de quatro safras de inverno/verão, no período de 2008 a 2010, em Jundiaí-SP. $1^{\text {a }}$ verão, $2^{\mathrm{a}}$ inverno, $3^{\mathrm{a}}$ verão, $4^{\mathrm{a}}$ inverno. 


\section{CONCLUSÕES}

1-A distribuição da chuva e sua concentração influenciaram na qualidade da baga ao longo das safras.

2-A qualidade da baga da uva aumentou no cultivo de inverno, sendo em nível gradual da variedade americana para a Vitis vinifera testada.

3-Nas condições microclimáticas, de solo e de planta, em que foi conduzido o experimento, o peso de cachos e a produção por planta decresceram da safra de verão para a de inverno.

4-Os níveis de reservas da planta foram afetados pelo cultivo contínuo, suscitando atenção quanto ao manejo da cultura em cultivo com dupla poda.

\section{REFERÊNCIAS}

AMORIM, D. A.; FAVERO, A. C.; REGINA, M. A. Produção extemporânea da videira, cultivar Syrah, nas condições do sul de Minas Gerais. Revista Brasileira de Fruticultura, Jaboticabal, v. 27, n. 2, p. 327-331, 2005. (

DELOIRE A.; LOPEZ, F.Y.; CARBONNEAU, A. Réponses de la vigne et terroirs. Eléments pour une méthode d'étude. Progrès Agricole et Viticole, Montpellier v.4, p.78-86, 2002.

DELOIRE, A.; OJEDA, H.; ZEBIC, O.; BERNARD, N.; HUNTER, J.J.; CARBONNEAU, A. Influence de l'état hydrique de la vigne sur le style de vin. Progrès Agricole et Viticole, Montpellier, v. 122, n.21, p. 455-462, 2005.

DRY, P.R. Canopy management for fruitfulness. Australian Journal of Grape and Wine Research, Adelaide, v. 6, p.109-115,2000.

FLEET, G. H. Wine microbiology and biotechnology. New York: Harvard Academic Publishers, 1994. $508 \mathrm{p}$.

FRANCIS, I.L.; KASSARA, S.; NOBLE, A.C.; WILLIAMS, P.J. The contribution of glycoside precursors to Cabernet Sauvignon and Merlot aroma. Washington: ACS, 1999. p.13-30.
GUROVICH, L.; PÁEZ, C. Influencia del riego deficitario controlado sobre el desarrollo de las bayas e la composición química de los mostos y vinos. Ciencia e Investigación Agraria, n. 31, p. 175-176, 2004.

ILAND, P.; BRUER, N.; EDWARDS, G.; WEEKS, S.; WILKES, E. Chemical analysis of grapes and wine: techniques and concepts. Adelaide: Tony Kitchener Printings, 2004. 110p.

JACKSON, D.I.; LOMBARDI, P.B. Environmental and management practices affecting grape composition and wine quality: a review. American Journal of Viticulture and Enology, Davis, v.44, n.4, p. 409-429 1993.

JACKSON, R. Wine science: principles and application. New York: Academic Press, 1994. 474 p.

LEÃO, P.C.S.; SILVA, E.E.G. Brotação e fertilidade de gemas em uvas sem sementes no Vale do São Francisco. Revista Brasileira de Fruticultura, Jaboticabal, v.25, n.3, p.375-378, 2003.

MANDELLI, F. ; BERLATTO, M. A. ; TONIETTO, J. ; BERGAMASCHI, H. Fenologia da videira na Serra Gaúcha. Pesquisa Agropecuária Gaúcha, Porto Alegre, v. 9, n. 1-2, p. 129-144, 2003.

OJEDA, H.; DELOIRE, A.; WANG, Z.; CARBONNEAU, A. Determinación del estado hídrico de la vid. Efectos morfológicos y fisiológicos de la restriçión hídrica em vides. Viticultura e Enologia Profissional, Barcelona, n.90, p.27-43, 2004.

PEDRO JR., M.J.; CAMARGO, M.B.P.; MORAES, A.V.C ; FELÍCIO, J.C.; CASTRO, J.L. Temperaturabase, graus-dia e duração do ciclo para cultivares de triticale. Bragantia, Campinas, v 63, n.3, p.447-453, 2004.

POMMER, C.V.; TERRA, M.M.; PIRES, E.J.P. Cultivares de videira. In: Pommer, C.V. (editor). Uva: tecnologia de produção, pós-colheita, mercado. Porto Alegre: Cinco Continentes, 2003. p.109-152.

ROLIM, G.S.; SENTELHAS, P.C.; BARIBIERI, V. Planilhas no ambiente EXCEL TM para cálculos de balanços hídricos. Revista Brasileira de Agrometeorologia, Santa Maria, v.6, n.1, p.133-137,1998. 
SANTOS, A.O.; KAYE, O. Composição quali-quantitativa da produção de Syrah cultivada sob estresse hídrico transiente. Revista Brasileira de Engenharia Agrícola e Ambiental, Campina Grande, v. 13, p. 272-281, 2009.

SANTOS, A.O. ; BERGAMASCHI, H.; BERGONCI, J.I.; ROSA, L. M. G. Improved modelling of maize water loss: a case study in Brazil. Agriscientia, Córdoba, v. 17, n. 1, p. 11-19, 2000.
THORNTHWAite, C. W., MATTER, J. R. The water balance. New Jersey: Drexel Institute of Technology, 1955. $104 \mathrm{p}$.

WAMPLE, R. L.; SANTOS, A.O.; KAYE, O. Implementation of calibrated near-infrared spectroscopy in precision viticulture and selective harvesting of wine grapes. In: MEETING OF THE AMERICAN SOCIETY FOR ENOLOGY AND VITICULTURE, 57., 2006, Sacramento. Proceedings... Davis: American Society for Enology and Viticulture, 2006. v.1. CD-ROM 